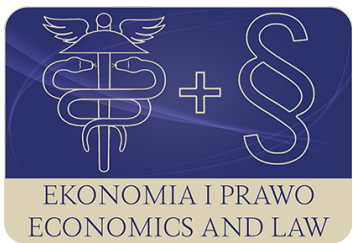

EKONOMIA I PRAWO. ECONOMICS AND LAW

Volume 16, Issue 4, December 2017

p-ISSN 1898-2255, e-ISSN 2392-1625

www.economicsandlaw.pl

EKONOMIA I PRAWO

ORIGINAL ARTICLE

received 13.06.2017; revised 01.12.2017; accepted 31.12.2017

Citation: Bojanowska, A. (2017). Improving the competitiveness of enterprises through effective customer relationship management. Ekonomia i Prawo. Ecomomics and Law, 16(4): 359-370. doi:10.12775/EiP.2017.025.

\title{
Improving the competitiveness of enterprises through effective customer relationship management
}

\author{
AGNIESZKA BOJANOWSKA \\ Lublin University of Technology, Faculty of Management, Department of Marketing, \\ ul. Nadbystrzycka 38, 20-618 Lublin, Poland \\ $\square$ a.bojanowska@pollub.pl
}

\begin{abstract}
Motivation: In today's market, it is impossible for the company to function without reference directly to the customer and building a relationship with him relevant. Today customers are very demanding and have a bigger knowledge about products and market then yesterday. Now enterprises have many opportunities in technology and methodology through which they can establish a relationship with the customer. There are numerous solutions in the field of CRM (Customer Relationship Management) software. Very important also are outside of the CRM software tools, such as creation of the proper organizational culture that is focused on the customer. Whether the customer relationship will increase the company's competitiveness in the market or not, depends on the effectiveness of customer relationship management in the company.

Aim: The author has taken up the topic of improving the competitiveness of enterprises through effective customer relationship management. She distinguishes company's competitiveness improving factors affected by the effective management of relationships with customers and determines the character of this impact. Additionally, in this article shall be defined determinants of the effectiveness of customer relationship management. These issues are supported by appropriate practical examples.

Results: The author of this paper has made some observations in a few enterprises and some interviews with managers and enterprise owners. They are qualitative research. They can not be considered in quantitative terms. The size of the sample was not verified, the author realizes that it is unrepresentative. Customer relationship management, as a strategy, system and philosophy, is not always known to entrepreneurs. Especially sole proprietorships apply CRM intuitively and not in a structured way. Not every company
\end{abstract}


uses appropriate software to collect customer data. But all managers are aware of the fact that building a lasting relationship with the customer raises competitiveness on the market. This happens even through the buzz marketing, increasing customer loyalty, rapid response to customer demand, also through the use of knowledge resulting from the data from the CRM system. Smaller companies should consider using some structured CRM solutions. Certainly it increased to their competitiveness at low cost. Whereas larger companies should focus on the use of their physical and human potential to improve the quali-

ty of customer relationships.

Keywords: CRM; marketing; competitiveness; customer; management JEL: M30

\section{Introduction}

In today's markets, we are dealing with an ever growing competitiveness among all subjects. Customers are more and more demanding, and their knowledge is still growing due to the global access to the Internet. Building proper relationships with customers is becoming a necessity for businesses if they want to maintain the desired level of profits. It is getting harder to build a long-term relationship with customers, as they become less and less loyal. Customers have continuous access to new offers. Enterprises shall communicate with customers about products and brands on a regular basis. For these reasons, today, companies should look for solutions that will help to maintain profitable customer-company relationships. Such a solution may be use of a comprehensive CRM (Customer Relationship Management) both within philosophy and system and other tools. The question arises about the scale and profitability of CRM applications depending on the size and profile of the company. The author of these article is trying to find a CRM solution that will ensure the greater competitiveness of smaller and larger companies. In the part of the article will there will be verified on the following thesis: It is possible to increase the company's competitiveness through the use of CRM solutions, and it may be distinguished depending on the size and profile of the company. To do this, she conducted a survey, which aims to show how the company is currently building relationships with customers and feeling of the need in this area.

\section{Literature review}

Definition of the concept of competitiveness is characterized by a scientific debate which has been going on for several decades, and still has not been finished. In accordance with the so-called standardized competitiveness defined in the OECD's (1994, p. 23) documents, which was later also applied by the European Union, 'competitiveness is the capability of companies, industries, regions, nations and supranational regions to create a relatively high income factor and relatively high employment levels on a sustainable basis, while permanently being exposed to international competition'. Although the definition of corpo- 
rate competitiveness has induced much less professional literary debates than national economic competitiveness, it cannot be considered as finally explained (Gal, 2010, p. 1).

The competitiveness of businesses can be measured in different ways. Traditionally, the main measures of competitiveness are defined in financial or marketing terms. For example, a competitive business might be expected to achieve one or more of the following:

- a higher growth rate (sales, revenues) than competitors and the market as a whole;

- higher-than average net profit margin (compared with others in the same industry);

- better than average returns on investment (e.g. ROCE, ROI) - again, compared with competitors;

- a high (and perhaps leading) market share - measured in either value or volume terms. The leading firms in a market usually enjoy a significant proportion of the available revenues or customer demand, unless the market is highly fragmented;

- the strongest brand reputation in the market - e.g. brand awareness;

- a clearly defined unique selling point ('USP') that enables the business to differentiate its product or service in the eyes of customers;

- significant access to, or control of, distribution channels in the market (e.g. products or brands that are widely stocked or demanded by intermediaries who provide distribution to the final consumers) (Riley, 2012).

The competitiveness of enterprises depends on many factors. Many authors have tried to make an attempt to systematize them. The results of one such attempt is shown in figure presented below (scheme 1). Because of the subject of this article important are issues such as markets, competitors and customers, use of communication network and human and physical capital us of efficiency. The possible impact of CRM on various factors will be discussed in the next section of this article.

\section{Methods}

For the purposes of this article there was surveyed 20 companies of various sizes, operating in various Polish cities. It was 10 single economic activities and 10 companies employing at least two employees. These companies operate in very different industries. The selection of companies for the study was intentional. It is the most typical case of non-random selection. It involves purely subjective choice of units surveyed in the sample, in the hope of obtaining the widest and most complete information. Inquiries about the possibility of conducting the study were sent to 43 companies. 20 of them responded and gave information that may be used for the purposes of this article. Firms have been assured of the anonymity of the study, as representation of their data would not help in any way to define the objectives of this paper. Anonymity to some extent, 
increases the credibility of answers. Companies mentioned in the article are identified by trades and size, which is important for this subject.

The aim of the study was to show how the company is currently building relationships with customers and feeling the need in this area. All this, of course, in the context of competitiveness. There were used two research methods: observation combined with the analysis of documents and direct interview with the managers or owners of the company. Research interviews belong to the methods of collecting information based on a process of mutual communication. The interview is a special kind of conversation, the aims to obtain a specific set of information. In an interview the most important role is played by the respondent whose deliberately induced responses are the primary source of information. The interviewer notes statements of the respondent. Direct interviews are divided into simple and deepened one; standardized and non-standardized. Standardization manifests a certain degree of uniformity and precision measuring instrument as method of interview. The higher the degree of standardization of the interview, the less freedom has a person who is interviewed and the greater role is being played by an instrument (e.g. a questionnaire). For this example, the interview is used with a low degree of standardization. The framework interviews with managers of selected companies gave 5 basic questions:

- Do you known the concept of CRM in your company? If so, to what extent the concept of CRM is used in your company?

- Is customer data in your company collected and processed in accordance to the philosophy of building long-term relationships with customers? Do you use a special software for this?

- Do you think that building a stable, long-term relationships with customers in your business make sense and enhances your competitiveness on the market?

- How does your company builds relationships with customers?

- How would you like to improve your relationship with your customers? Of course, it was possible to expand topic in the context of the interview.

\section{Results}

Before the discussion of CRM begins it is important to mention a few words about the modern marketing. Today's marketing is not a function; it is a way of doing business. Marketing is not a new ad campaign or aggressive promotion. Today's marketing has to be all pervasive, part of everyone's job description, from the receptionists to the board of directors. Marketing is also about how to integrate the customer into the design of the product and to design a systematic process for interaction that will create substance in relationships. In a competitive world, companies have to work hard to have any added value. They have to work with their customers to discover ways to run the business more effi- 
ciently for themselves and more effectively for the customers (Zineldin, 2005, pp. 333-334).

Customer relationship management (CRM) has been widely regarded as a company activity related to developing and retaining customers through increased satisfaction and loyalty (Xu \& Walton, 2005, p. 955). CRM is heralded by some marketing academics and practitioners as the new paradigm of marketing. CRM is the implementation of an effective customer-centric strategy within an organization in order to create superior value that is required for sustenance of the exchange process between the organization and its target customers in a competitive market (Thuo, 2011, p. 1). Various studies demonstrate that CRM improves understanding of consumer behavior and the delivery of personalized services, which supports the adaptation, effectiveness and efficiency of products and services (Ab Hamid \& Kassim, 2004, pp. 103-108). The essence of CRM captures scheme 2.

Information technology (IT) is constantly implemented by organizations to help improve competitiveness although it seems that as new IT-based systems and concepts become available, they are devoured by organizations with little thought for existing and past experiences (Light, 2003, p. 603). The question should be whether the CRM software belongs to this type of technology. Is it necessary to achieve adequate competitiveness of every business? Companies that use CRM software generally are satisfied with their return on investment and CRM initiatives frequently result in increased competitiveness for companies, as manifested in their higher revenues and lower operational costs. Finally, CRM applications help organizations reach and then assess their profitability with measures such as repeat purchases, dollars spent and longevity (Venturini \& Benito, 2015, p. 863).

It is important to define the goal of implementing CRM in the businesses. By doing so, organizations can broaden their CRM focus by allowing marketing as well as sales and services to work together efficiently to achieve the ultimate goal which is to serve the customers better with high quality (Nguyen \& Newby, 2007, pp. 104-105). Freeland (2003, p. 43) proposed the following group of goals:

1. Guiding principles. Organizations who want to reshape the focus of their CRM programs should follow these three guiding principles:

- customer experience is essential to creating brand value. Organization should do something about logos, catchy styles, or memorable commercials that can give customers the impression or awareness that it is their product or service;

- customer insight should inform and drive customer treatment. Every contact that the company has with its customers determines the economic value of its future because if the customer is happy, he or she will be back;

- CRM programs should be executed in a pragmatic way that mitigates financial and delivery risk. CRM programs should be planned according to both financial ability and risk elimination to the best of the company's practice. 
It is not to be built with elegant capabilities, or the latest version of the software, or serving the customers at any cost. However, it must be practical, realistic, and provide the capabilities that the users need.

2. Components for success. To achieve these, organizations should organize their CRM initiatives around the following four components:

- setting the strategy. Identifying the customers that the company wants based on its existing business model and corporate mission;

- gaining customer insights. The ability to understand customer needs and accurately predict customer behavior;

- realizing greater value from customer contact activities. Improving the quality of customer interactions while at the same time driving down the cost of service;

- transforming marketing. Identifying where money is being wasted or misspent on the market while ignoring the 'market noise' to efficiently quantify and optimize all resources in ways that most companies have not yet attempted.

It can be said that the effectiveness of customer relationship management depends largely on a correctly matched aims of CRM. The achievement of most of these objectives in fact depends on whether the company will be competitive or not. So all CRM objectives in organization can lead to a success in the market regardless of the chosen strategy. This also applies to factors determining business competitiveness from the previous part of this article.

Satisfaction and loyalty, from CRM definition, are keys to attract customers which is also very important to competitiveness. Therefore there was examined how companies establish and build their relationships with customers. Nowadays knowledge of new methods and technology is important even in a very small business. That's why all managers were asked about knowledge of CRM. Most of small business managers in Poland doesn't even now about customer relationship system and philosophy but they intuitively apply the principle of building long-term relationships with customers. Sometimes it can be more effectively than the use of complicated procedures and software because small companies usually have a relatively small number of customers. For the purpose of this article there were tested ten one-man businesses form a different trade including: the energoterapist, two hairdressers, the small gluten-free bakery, the law firm, the photographer, the manicurist, the business consultant, the specialist of European funds, the psychotherapist and the estate agent. They operate independently and know all their customers personally. These are different trades and have a different terms of competitiveness on the market. For example, some of these activities are conditioned by legal restrictions and the entrance to the market is far more difficult. This makes professions, such as a real estate agent, enjoy greater trust and loyalty of customers than the sample hairdresser. It is easier to build customer data base when people have to provide some personal data. For example, the law firm has compulsory register of customers. All managers in these companies said that they want to build 
some relationships with customer. Sometimes they are not even able to describe how they have been doing it so far, because it happens almost automatically. Sometimes they complained that the nature of the activity does not allow for maintaining long-term relationships with customers. For example, a real estate agent can rather rely on a buzz marketing but not on a regular contacts with the same customer. Direct contacts with customers were the most important for these companies. Regarding competitiveness, it was indicated as its indicators: customer loyalty to a particular person performing the service and to the place of execution. Small businesses see competition as an opportunity rather to stay on the market and possible development. Single enterprises rarely apply any CRM software. Probably they do not see the need or think the cost is too high for their company. Only companies that are forced to do so by legislation, conduct structured customer database. Information about customers tend to be stored in notebooks and calendars. Rarely are processed on purpose.

For the purpose of this article there were tested ten bigger then one-man businesses companies form different trade: the production of special purpose machinery and technology, the consulting and IT audit, the nonpublic nursery, the chemical company, the cafeteria, the restaurant, the e-commerce food for animals, the vehicle control station, the private medical center, the board games shop. Managers of larger companies know what is CRM. They say that their companies are using solutions for customer relationship management. In most cases they do not have implemented CRM software, but plan to buy it. Small entrepreneurs rarely find something they would like to improve in their relationships with customers. The situation is different in larger companies. Managers of larger companies plan the development towards building lasting relationships with customers. Some of them would like to establish a closer dialogue with customers and understand that the high price of goods and services, in their case, has a high quality. Others want to increase the customer's conviction of the brand value and reputation of the brand. There were also voices that pointed to the need for faster response to customer needs, faster response to customer requests and a more personalized response to the customer. That can be achieved by successful CRM implementation. But still, most major companies rely on marketing departments that use only a few percent of the opportunities offered by the system and the philosophy of CRM. In terms of competitiveness, more companies have developed strategies covering largely build lasting relationships with customers. Managers agree that CRM supports these relationships by enabling rapid response to customer needs. In the CRM system this can be achieved by using appropriate software and special procedures. The owners of some companies also admit the importance for the competitiveness has become the attitude of organizational culture on the customer. 


\section{Conclusion}

Research carried out for the purposes of this article and literature studies allowed for the implementation of the objective which had been set at the beginning of the article. It is possible to improve company's competitiveness by effective CRM. Customer relationship management as a strategy, system and philosophy are not always known to entrepreneurs. Especially sole proprietorships apply CRM intuitively and not in a structured way. Not every company uses an appropriate software to collect customer data. But all managers are aware of the fact that building a lasting relationship with the customer raises competitiveness on the market. This happens even through a buzz marketing, increasing customer loyalty, rapid response to customer demand, whether through the use of knowledge resulting from the data from the CRM system. The effectiveness of CRM in a company depends on the effectiveness of its implementation. It is important to realize the need to build customer relationships with every employee. It is important to select the correct purpose of implementing CRM, and they may be different. It depends on the extent to which CRM will be able to support the competitiveness of enterprises. Smaller companies should consider using some structured CRM solutions. Certainly, at low cost, it increases their competitiveness. Whereas larger companies should focus on the use of its physical and human potential to improve the quality of customer relationships. Taken subject is quite broad and can be carried out on this extended study. It can be dealt with in other publications. Based on the knowledge of CRM systems and the experience of research, you can propose in tabular form how Polish companies could use specific CRM instruments to increase its competitiveness (table 1).

\section{References}

Ab Hamid, N.R., \& Kassim, N. (2004). Internet technology as a tool in customer relationship management. Journal of American Academy of Business, $4(1 / 2)$.

Chen, I.J., \& Popovich, K. (2003). Understanding customer relationship management (CRM). Business Process Management Journal, 9(5). doi:10.1108/14637150310496758.

Freeland, J. (2003). The ultimate CRM handbook: strategies and concepts for building enduring customer loyalty and profitability. New York: McGraw-Hil.

Gal, A.N. (2010). Competitiveness of small and medium sized enterprises: a possible analytical framework. Hungarian Electronic Journal of Sciences, ECO-100115-A.

Gucel, C., Begec, S., \& Iveta, S. (2013). Competitivness - a key to business viability. Proceedings of Proceedings of the XIV International Scientific Conference: Creating the Future. Riga: Turība University. 
Light, B. (2003). CRM packaged software: a study of organisational experiences. Business Process Management Journal, 9(5). doi:10.1108/14637150310496712.

Nguyen, T.U.H., \& Newby, J.S.S.M. (2007). Strategies for successful CRM implementation. Information Management \& Computer Security, 15(2). doi:10.1108/09685220710748001.

OECD. (1994). Globalisation and Competitiveness: Relevant Indicators. Retrieved 02.03.2017 from http://www.oecd.org.

Riley, J. (2012). Measuring the competitiveness of a business. Retrieved 02.03.2017 from https://www.tutor2u.net.

Thuo, J. K. (2011). Customer relationship management practices and competitiveness of commercial banks in Kenya. Unpublished doctoral dissertation. University of Nairobi, Kenya.

Venturini, W.T., \& Benito Ó.G. (2015). CRM software success: a proposed performance measurement scale. Journal of Knowledge Management, 19(4). doi:10.1108/JKM-10-2014-0401.

$\mathrm{Xu}, \mathrm{M}$., \& Walton, J. (2005). Gaining customer knowledge through analytical CRM. Industrial Management \& Data Systems, 105(7). doi:10.1108/02635570510616139.

Zineldin, M. (2005). Quality and customer relationship management (CRM) as competitive strategy in the Swedish banking industry. The TQM Magazine, 17(4). doi:10.1108/09544780310487749.

\section{Acknowledgements}

Author contributions: author has given an approval to the final version of the article.

Funding: this research was fully funded by the Lublin University of Technology, Faculty of Management, Department of Marketing statutory sources. 


\section{Appendix}

\section{Table 1.}

\section{How Polish companies could use specific CRM instruments to increase its competitiveness?}

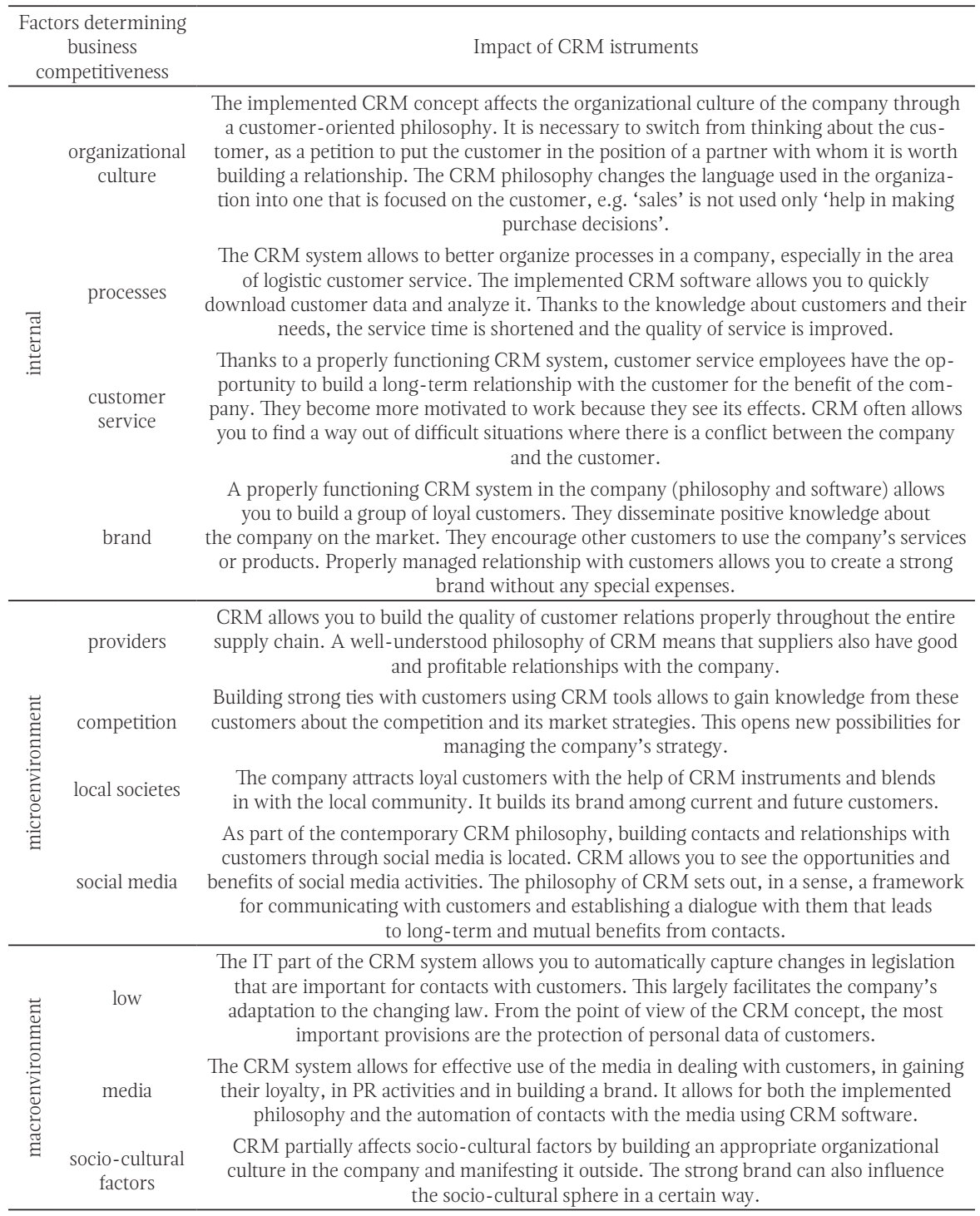

Source: Own preparation. 


\section{Scheme 1 .}

Factors determining business competitiveness

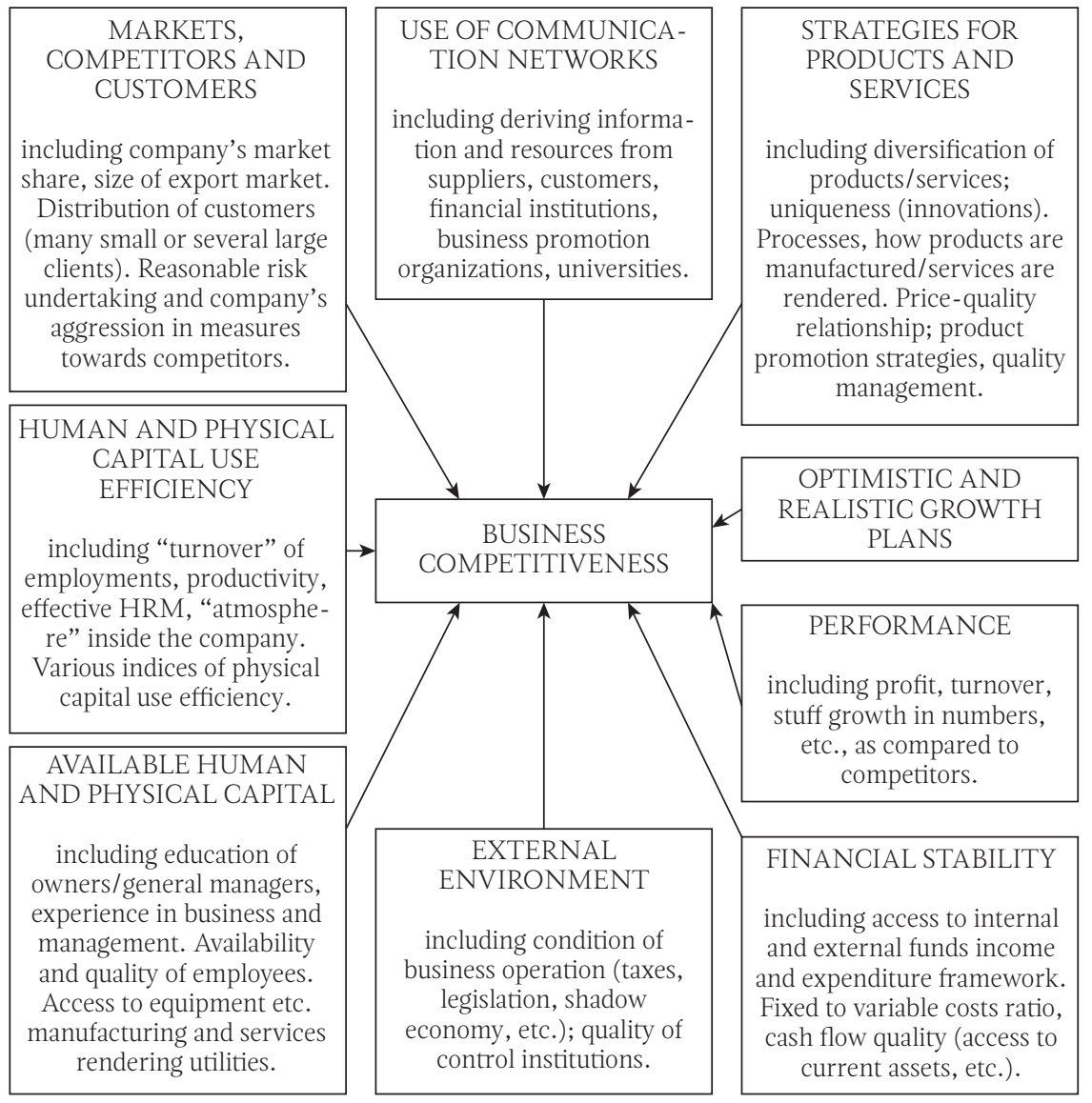

Source: Own preparation based on Gucel et al. (2013, p. 166). 
Scheme 2.

Factors determining business competitiveness

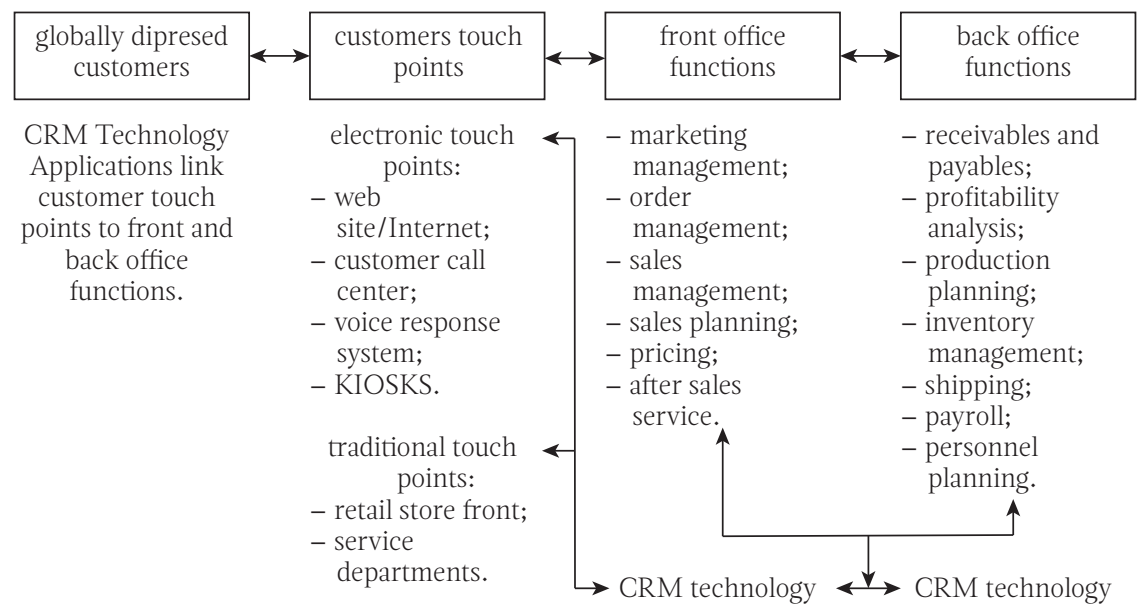

Source: Chen \& Popovich (2003, p. 674). 